\title{
El plástico en el arte popular y en el arte moderno contemporáneo en Guatemala
}

\author{
Carlos René García Escobar \\ Antropólogo. \\ Universidad San Carlos de Guatemala
}

Desde el pasado siglo XX, específicamente después de la II Guerra Mundial, Centro América, como muchos territorios nacionales del llamado III Mundo o también como parte de los denominados países subdesarrollados, ha sufrido con más intensidad que nunca la penetración desmedida y abusiva de los intereses económicos y políticos de las potencias autodenominadas "superdesarrolladas" en términos de penetración de sus mercados de productos industrializados, en el contexto de sus modernas tecnologías auxiliándose del usufructo de aranceles de exportación/importación favorables a las megaindustrias mono y polipólicas, en desmedro de las pobres y débiles economías de estos pueblos tercermundistas.

Este fenómeno de claro carácter capitalista de la producción mundial ha afectado los hábitos de consumo de las sociedades que bajo su influjo gravitan en un capitalismo dependiente que les permite a los países de Economía dominante toda clase de desmanes incontrolados por nadie ni poder autónomo capaz de cerrar filas ejercitando el derecho de autonomía y libre determinación pues, las libres democracias y las relaciones diplomáticas y comerciales amañan los intentos de accionar con libertad de pensamiento y de auténtico libre comercio. Tales democracias y Tratados de libre comercio sólo son fachadas de un triste sometimiento de las voluntades oficiales de los gobiernos constituidos ya sea "democráticamente" o por la fuerza de imposiciones militares de dentro y fuera de las naciones.

Como fenómeno de inequívoca penetración de intereses capitalistas extranjeros ha permeado durante los recientes lustros una paulatina intromisión de tipo comercial fundamentalmente pero con la máscara de la innovación cultural que ha transformado los productos culturales nacionales caracterizándolos con innovaciones de tipo industrial por un lado (en el orden de las artesanías por ejemplo) y, a su vez, por intercurso de los massmedia (medios de comunicación para las masas) las poblaciones pertenecientes a estas socie- 
dades dependientes del capital internacional, han adquirido hábitos nuevos tendientes a un cambio de conciencia identitaria que las conduce a olvidar o abandonar hábitos y comportamientos de corte tradicional como herencias ancestrales asumidas a través del pasado reciente y antiguo, en aras del consumo de productos y quehaceres nuevos que transforman estas identidades e inciden en gustos y hábitos que conducen a su vez en el deterioro físico de los organismos vivientes y las personas. En otro sentido el plástico se ha introducido como elemento coadyuvador para otorgar sentido estético y simbólico en expresiones materiales con pretensiones artísticas y de mensaje social o sociológico como veremos aquí más adelante.

Dice Néstor García Canclini que en México, “—además de existir una vasta producción en las industrias culturales habitualmente identificada como tales: editoras, radio, cine, televisión y video- se intensificó la industrialización, o la incorporación a circuitos tecnológicos y masificados de otras actividades: del teatro a las telenovelas, lo espectáculos en vivo, el turismo e incluso las artesanías." En el caso de las artesanías, que concebimos como artes populares, algunos sectores hemos criticado la "degradación masificada a la base de la alteración de los diseños tradicionales. Fenómeno que ha venido ocurriendo en Guatemala desde hace unos veinte años cuando empezaron a aparecer las fábricas de artesanías llamadas por el mercado neoliberal como "neoartesanías" y cuya venta ocurre en centros comerciales exclusivos como los metamercados y los mercados para turistas de las grandes ciudades y poblaciones turísticas guatemaltecas y ahora de toda Centroamérica. En tales mercados pueden observarse todo tipo de alteraciones y reinvenciones de los diseños tradicionales dando paso al gusto turístico globalizado y transformando desde esa visión mercantilista las antiguas identidades culturales de los guatemaltecos en general explotando la creatividad popular en desmedro de las herencias culturales que han dejado de funcionar a la base de la creación de nuevas necesidades de uso de los artefactos artesanales.

Canclini observa que la incorporación de las artesanías tradicionales a una lógica industrial "genera preguntas acerca de cómo combinar el valor mercantil con el valor simbólico que tales bienes y mensajes tienen como representativos de tradiciones comunitarias y prácticas de identificación social. Existen dudas - dice - aún irresueltas respecto de la propiedad intelectual y los derechos de autor - cómo se articulan o entran en conflicto la propiedad comunitaria, la autoría individual y el copyright - que aproximan estos campos a la problemática de las industrias culturales." 
El problema de dilucidar toda una serie de conveniencias e inconveniencias entornadas por una nebulosa de inconformidades que tienen que ver con el bienestar inmediato y mediato de los artesanos productores en primer lugar, luego con los intermediarios, (entre ellos los comerciantes y los funcionarios del Estado) y finalmente con los consumidores, en su mayor parte turistas, es planteado por Canclini en los siguientes términos: "Durante el siglo XX, como en otros países con poderosas culturas populares, (como Guatemala), en México hubo que atravesar largos debates para ampliar la concepción elitista de cultura y lograr que fueran reconocidos como parte del patrimonio nacional los productos artesanales, étnicos y de grupos populares urbanos. Ahora, el desafío es comprender y valorar la reutilización industrial y mercantil de bienes cultos y populares tradicionales en circuitos transnacionales. La televisión, los videos y las redes digitales ponen a disposición de públicos próximos y lejanos las pirámides y los centros históricos, así como obras de arte para personas que nunca entraron en un museo. Podemos comprar artesanías por Internet usando tarjetas de crédito y hasta recibir la certificación digital... sobre los diseños tradicionales. La mayor parte de las artesanías sigue circulando en mercados y tiendas de la propia región, los productores no se organizan empresarialmente ni llevan inventarios, pero un sector creciente se ha convertido en asalariado de grandes talleres y empresas, donde los formatos originales son reelaborados por diseñadores, se busca la exportación y las artesanías aparecen asociadas a paquetes turísticos, gastronomía "de sabor local" y música étnica. En tales condiciones, la problemática artesanal se aproxima a la de las industrias culturales. ¿Cómo interactúan los derechos de los comerciantes y consumidores, de los museos y los sitios de la web, con los derechos de los grupos indígenas o populares a los que históricamente pertenecen tales bienes culturales?

Dada la problemática aquí planteada como una premisa real que afecta los procesos educativos e identitarios de los guatemaltecos, cabe preguntarse también acerca de las políticas adecuadas para el control resolutivo de los problemas socioculturales que devienen de estos nuevos giros que ha producido la industrialización de la cultura. Porque no bastan las declaraciones de patrimonio cultural que el Gobierno otorga como una instancia pretendidamente protectora sobre los saberes populares a la base de solicitudes de personas interesadas en obtener resultados económicos debidos a la mercantilización turística de los bienes culturales así declarados. El problema está en que este tipo de declaraciones no resuelve las insatisfacciones de la vida paupérrima de los artesanos productores en su calidad de creadores y autores 
de arte popular individual o en serie. Y no únicamente en el mundo de las artesanías, sino también en el de las representaciones danzarias, teatrales y musicales, que son las expresiones de la cultura popular y tradicional más conocidas desde todos los puntos de vista posibles.

El otro problema que se plantea es el de los derechos de autoría que les corresponden. Nadie, desde la Unesco, pasando por los funcionarios de toda índole de instituciones relacionadas con este tema, los maestros de todos los órdenes del sistema educativo nacional, hasta incluso los mismos productores de artesanías originales, toman en cuenta esta instancia que corresponde a los derechos de la autoría artística popular y ahora industrial. El argumento mejor esgrimido y que he escuchado en todos los debates académicos a los que he asistido desde los años ochenta es el de que un producto artesanal y artístico producido desde la base popular de origen es anónimo porque su autoría se pierde en la noche de los tiempos y por lo tanto no existe persona alguna a quién reconocerle ese derecho de producción originaria. Por eso es que hemos propuesto desde esos años la categoría de "portadores" en tanto que sus conocimientos sobre las técnicas y concepciones artísticas de sus productos artísticos artesanales son heredados generacionalmente por las vías de las líneas familiares y comunitarias más cercanas a quien conlleva el conocimiento heredado y produce el hecho artístico tradicional. Esto sólo se constata y reafirma mediante la investigación y documentación adecuada que nos provea un inventario sistematizado de los productores de arte popular tradicional en Guatemala.

En este sentido, para resolver en algo la problemática del desconocimiento existente sobre los verdaderos artistas creadores de arte popular, ignorados deliberadamente por las instituciones privadas y estatales que sólo ven el producto y no al productor, la tecnología contemporánea actual nos ofrece posibilidades que deben ser adecuadamente aprovechadas. Son aquellas de fácil reproducción y difusión como los videos y la Internet que son propicios para facilitar de inmediato la reproducción mediática de los diseños artesanales y la música tradicional, fácilmente convertibles en prósperos negocios mediáticos, y de lo cual ya existen numerosos ejemplos en el Mercado nacional e internacional. Es claro que aun no existen normas de protección para el patrimonio cultural en estas novísimas instancias de la tecnología y de ahí que fácilmente son apropiables por individuos e instituciones sin la ética necesaria para la protección de los bienes culturales de los guatemaltecos. 
Para una mejor y más completa ilustración de lo dicho extractamos del libro Repensar Guatemala, editado por la UNESCO y la Universidad Landívar, en el marco Mundial de Filosofía en Guatemala, las siguientes afirmaciones que nos hablan concretamente de los nuevos fenómenos de las expresiones artísticas innovadoras que esta nueva situación histórica de la sociedad guatemalteca está produciendo. Esta problemática social provocada por la industrialización del Plástico ha sido considerada por la UNESCO en un texto que describe el proceso tal como sucedió años atrás en el Altiplano guatemalteco de la manera siguiente:

El siglo pasado hubo algo extraño en el cielo sobre el Lago. Por primera vez una avioneta surcó esas nubes, hoy en día un hecho común en ese paraje que para ese entonces era totalmente inhóspito. Los habitantes de las comunidades inmediatamente identificaron un objeto desconocido que invadía su contexto y que traía consigo, sin que ellos lo supiesen, los designios de "la era moderna”. Este singular evento no hizo más que desencadenar una serie de debacles, el pánico inundó a la comunidad e hincados en las calles muchos esperaban una catástrofe. Esa marea de pánico indujo rituales con los cuales el "pom", consumido por las llamas, acompañado de "la chirimía" se elevó a los cielos; plegarias, lágrimas y súplicas emanaban de la conmocionada masa. Había algo extraño en el cielo.

Desde entonces "lo moderno" ha invadido paulatinamente sus vidas, sus costumbres y su cultura. Poco a poco el barro se volvió caduco y el plástico fue tomando su lugar. En los hogares los guacales guardan el agua, ya no las vasijas; ahora el plástico toma la forma de aquellos recipientes de dos orejas en los cuales las mujeres traían agua del lago o del río cercano. Ahora toneles, cubetas y guacales yacen en los patios llenos del vital líquido como la "reserva" para lo vital. La comunidad que yace junto al Lago carece de agua potable y otros problemas de carácter natural, otro irónico contraste de la polarización. La sociedad se ha emplasticado.

Unos objetos son desplazados por otros: el cuero de las sandalias se cambió por el látex y el comal fue desplazado por algún electrodoméstico. En el contexto de lo rural, la chancleta de la marca "Suave chapina" fue un elemento que se popularizó durante el conflicto armado que connotaba la pobreza de las comunidades que fueron afectadas por la guerra. 
Esa eterna confrontación entre los dos extremos ideológicos continúa menguando la comunidad que se ve inyectada de "nuevos" objetos que no producen la misma reacción de aquel avión que alguna vez produjo rezos, porque con el tiempo se volvió más común el objeto "nuevo" que seduce el abandono de lo hasta entonces conocido.

Las comunidades con el acaecer del tiempo dejan tras de sí objetos olvidados que cuentan su historia. Hoy en día esos objetos son "plásticos", objetos en serie creados en fábricas, distantes de las vasijas de barro imbuidas con la individualidad de aquellos orfebres de oficio sagrado. Lo masivo ha reemplazado la individualidad del guatemalteco que busca su identidad a través de los objetos de marca, dividido por la constante tensión de "lo local" y lo de "afuera".

En ése, ahora imprescindible viaje de ida y vuelta, de allá para acá, el paisaje natural se ve "filtrado" por el polarizado, esa barrera gris (vidrios emplasticados) que cubre la ventana y que de manera trágica separa lo de adentro de lo de afuera. Es el filtro que nos aplana un paisaje colorido convirtiéndolo en blanco y negro, que no nos deja apreciarlo del todo y que es el constante compañero de todo viaje de ida y vuelta. El polarizado implica que los que están afuera no vean a los que están adentro, pero para los de adentro conlleva la consecuencia de no poder apreciar a totalidad el paisaje que está afuera. El paisaje de la eterna primavera se ha convertido en el eterno conflicto entre dos extremos, siendo el polarizado otra acción que induce esa brecha.

El artista es, entonces, aquel viajero que transita el péndulo entre su comunidad y la ciudad, que siendo testigo de los cambios en los procesos culturales de la sociedad guatemalteca logra canalizarlos a través del arte. El artista reinterpreta, re-construye, re-presenta y re-plantea esos cambios que atestigua para transmutarlos en objetos de arte.

Las comunidades que sobresalieron en cuanto a este tipo de "testigos" fueron Santiago Atitlán (Juan Sisay), San Pedro La Laguna (Rafael González y González), San Juan Comalapa (Andrés Curruchiche y Francisco Telón). Estas figuras que surgen en el campo artístico del siglo pasado ejercen hasta la fecha una influencia de peso en la escena del arte folclórico guatemalteco (primitivista). Fueron testigos de una época. El conglomerado de las obras de arte naif generadas por estos exponentes constituye entonces el testimonio de antaño. Nos proporciona un testimonio de sus vidas, sus comunidades y 
costumbres; por ello son conocidos como los maestros de la realidad. Muchos artistas aún escogen seguir este movimiento de arte y consecuentemente perpetúan esta corriente costumbrista.

En la actualidad, una creciente generación de artistas rompe la continuidad del Arte Naif replanteando la visión del arte contemporáneo indígena guatemalteco y, con ello, planteando la unión de esas estilos fragmentadas, estos abarcan desde el Arte Folclórico hasta el arte popular, señalando así el camino hacia el fin de la polarización del arte índigena. Los "testigos" de la contemporaneidad guatemalteca traen consigo el retorno a la comunidad y el planteamiento del trabajo comunitario, una dinámica existente en el área rural, que a través de su trabajo aborda el arte en sus diferentes ramas (literatura, plástica y música).

El artista es testigo del proceso de transformación de la cultura que sobrellevan las áreas rurales. Esos cambios vienen de la mano del block (que sustituye al adobe), del plástico (que desplaza al barro), del hierro (que reemplaza a la madera), lo desechable y lo re-tornable.

El reto del arte contemporáneo es plantar la semilla para que los extremos divididos se unan, para que el retorno no fomente la fragmentación sino que logre la cohesión de los dos extremos, reconociendo nuestra hibridez y partiendo de ella hacia una autenticidad de pensamiento y acción.

La tristeza del paisaje filtrado por el polarizado se perpetúa. Los detonantes han sido muchos, la conquista, la guerra, el narcotráfico y la ingobernabilidad. Nuestro reto es continuar ese retornar a lo auténtico que permita que ese re-pensar se geste en medio de acciones que continúen favoreciendo el fin de la brecha. Debe haber un retorno a lo sagrado y a lo auténtico. Llegar a lo primigenio y partir de allí para re-pensar a la nación.

El artista contemporáneo plantea una nueva forma de comunicar a través de un lenguaje propio. Cada testigo posee un lenguaje único y con él se arma para enfrentar a la enorme brecha que amenaza con devorar a esta sociedad. El sentido de pertenencia a algo más grande o "mayor" que el propio ser ancla al artista y lo impulsa a seguir "hablando" este "lenguaje" sin desistir porque, aunque su labor permanezca bajo el manto de lo invisible, el tiempo va concretando su obra como tangible más allá de las fronteras y los medios inmediatos. En este sentido se presenta actualmente en galerías españolas una exposición 
novedosa en la que participa uno de los artistas jóvenes guatemaltecos, de extracción étnica tzutuhil, Benvenuto Chavajay, quien consciente de su situación como artista en el medio guatemalteco se define concretamente explicando su producción artística, imbuída por el uso del Plástico de la forma como sigue:

\section{Material como concepto}

A lo largo, como artista de la neo-post-guerra, he sido testigo de los cambios y fenómenos que adolece el pais y la cultura. En el principio era el barro el material que por excelencia lograba materializar la estrecha unión entre la comunidad y su entorno-natural y etéreo, con el devenir de los cambios el barro fue reemplazado por el plástico. Este modelo se repite en las demás comunidades de Guatemala y en Latinoamérica. Es el plástico el material que viene a incorporarse a todos los aspectos de la vida cotidiana, de algún modo todo se ha "emplasticado" "retornable" "desechable".

Teniendo esto en mente los objetos transmutados por mis manos son de plástico, éste material que se ha incorporado a nuestra cultura y su uso parece propagarse a todos los aspectos de nuestras vidas, por lo que pareciera que nuestras vidas se han tornado "desechables". Testigo de esto, me ubico desde una perspectiva neutral, proponiéndome materializar a través de los objetos de arte éstos cambios que adolece mi entorno inmediato. A diario miles de personas van y vienen. Muchos se dirigen de un extremo de La Ciudad a otro, mientras otros y muchos, realizan la travesía de La Ciudad a alguna comunidad en el interior y viceversa. La macrocefalia de Guatemala nos empuja a recorrer a diario esos largos trayectos, durante los cuales brotan experiencias que en mi caso particular se traducen en objetos de arte. Entre el ir y venir de mi comunidad a la ciudad y de regreso, el paisaje de mi viaje se compone de todos los tonos de verde imaginables. La camioneta se convierte en un refugio, una especie de Templo, que a su vez permite al pasajero apreciar el paisaje guatemalteco.

\section{Camuflaje}

A raíz del Conflicto Armado en Guatemala (1960-1996) el camuflajeado se afianza en el imaginario colectivo como un símbolo del terror. En la Post Guerra (1996-2009) el significante del símbolo sufre un cambio en nuestro contexto, de un símbolo de respeto se transforma para formar parte de la moda popular. Hoy en día forma parte de una expresión artística. La tela ca- 
muflajeada ya posee la gama de colores por lo que constituye un pantone existente y vigente en el imaginario, esos mismos colores son parte del paisaje natural de Guatemala, todo viajero los contempla en su ir y venir. El camuflaje en tela implica hoy en día un proceso industrial y es allí donde se retoman a su vez más temas de la sociedad guatemalteca la "industrialización” y las "maquilas".

\section{Guacal}

El "guacal" como objeto representa el cambio de los materiales de los utensilios, del barro al plástico, un profundo cambio cultural, hemos "emplasticado". Todos los objetos son de plástico. Los objetos arqueológicos son transformados de nuevo por la "industrialización" y la "comercialización". Los arqueólogos en el futuro encontraran los vestigios de nuestra sociedad "emplasticada" (guacales, chancletas de huele suaves chapinas, llantas, bolsas plásticas etc objetos industriales retornables) y ya no los majestuosos objetos de barro producto de las civilizaciones antiguas. A su vez se retoma la temática de la Cuenca del Lago, el guacal es lugar de reposo del agua. Los pueblos alrededor del Lago que se ven envueltos en una de las grandes ironías de nuestra sociedad: estar cerca de un cuerpo de agua y careciendo de agua potable. Al ser privados de éste vital líquido es el guacal el objeto común en los hogares que a su vez se vuelve el contenedor de este indispensable recurso de la vida cotidiana. Los utensilios "plásticos" de nuestra cotidianidad adquieren un carácter "desechable" y "retornable", proyectándose así como un testimonio de los cambios culturales que adolece. Y termina diciendo: "Como artista no puedo más que ser testigo imparcial de los fenómenos culturales, siendo uno de mis objetivos transmitir los cambios que atestiguo”.

He aquí entonces, las nuevas formas de expresión artística que los nuevos fenómenos polarizantes, a la vez homogenizantes, de la globalización económica, comercial y cultural, están produciendo en Guatemala impulsados por la industria cultural. Se trata de nuevos conceptos de identidad que urgen nuevos análisis para su comprensión adecuada.

Nueva Guatemala de La Asunción

16 de febrero de 2013

Ponencia presentada por el autor en el IX Congreso Centroamericano de Antropología, del 18 al 23 de febrero del 2013, en la Universidad San Carlos de Guatemala. 


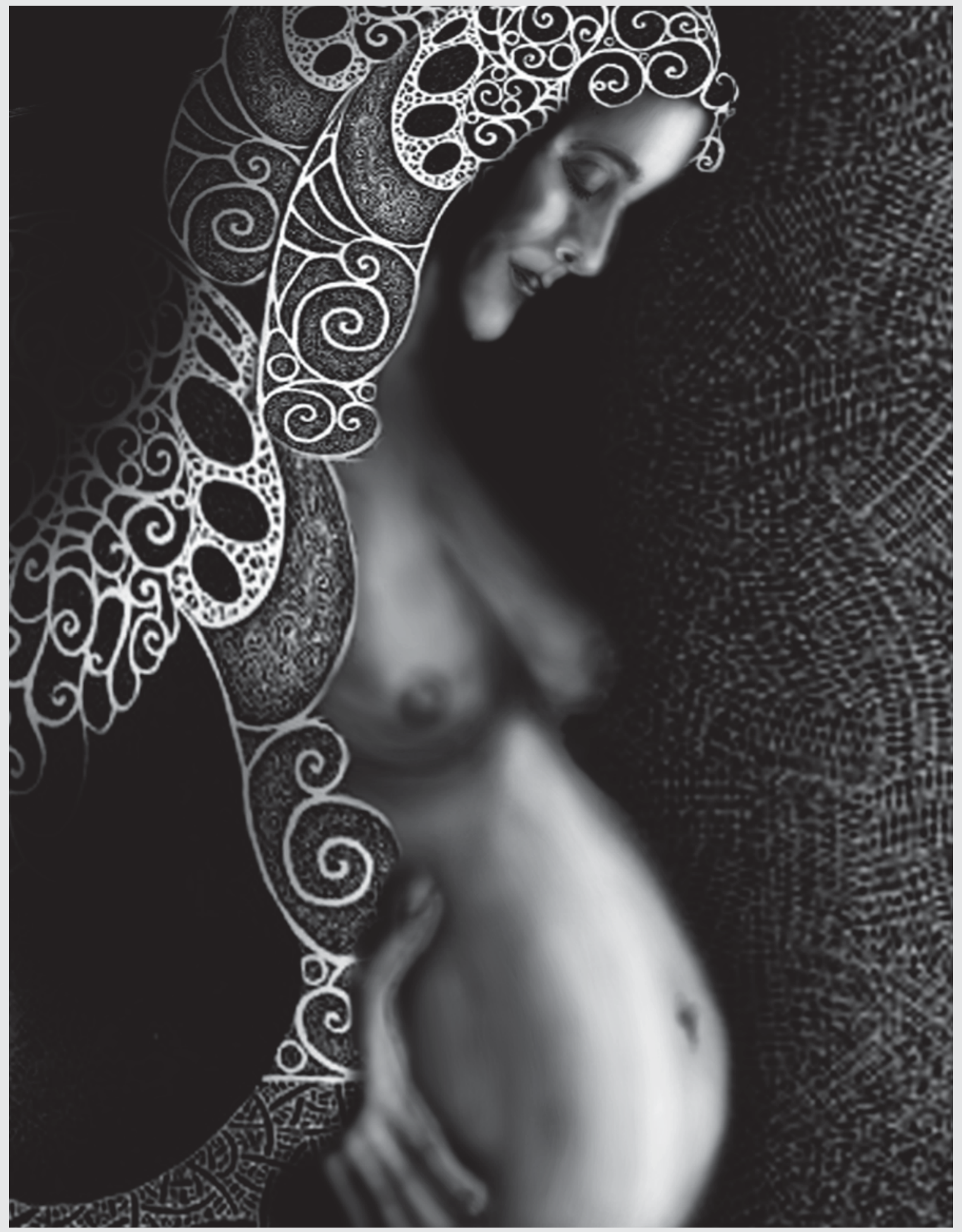

Ilusión. Técnica digital, 8.5”x 11”. Rita Araujo. 2013. 